\title{
A simple volumeter for small invertebrates
}

\author{
G. Persoone \\ Laboratory for Ecology, State University of Gbent; Ghent, Belgium
}

KURZFASSUNG: Ein einfaches Volumenmeßgerät für kleine Wirbellose. Es wird ein Gerät zur Messung des Volumens von kleinen Wirbellosen beschrieben, das leicht zu konstruieren und einfach zu handhaben ist. Es basiert auf dem Prinzip der Verdrängung einer Wassersäule und gestattet, Volumina bis zu etwa $0,01-0,005 \mathrm{~cm}^{3} \mathrm{zu}$ messen.

\section{INTRODUCTION}

The displacement technique for measuring the volume of plankton catches is well established, and a number of papers have been published describing suitable apparatus for this purpose including those by Frolander (1957), and Yentsch \& HeBard (1957). Gnanamuthu (1952) reviews several papers dealing with equipment for measuring the volume of small aquatic animals and discusses his own volumeter.

The apparatus here described employs a water column and is, therefore, more convenient to handle than previous designs which used a mercury column. It is inexpensive and simple to construct, and will measure to 0.01 or even $0.005 \mathrm{ccm}$. We have found it most useful in quickly measuring the volume of polychaetes or oligochaetes, small bivalves, small crustaceans, etc.

\section{DESCRIPTION}

The principal part of the device (Fig. 1) is a Y-shaped glass tube, the left leg of which is fitted with a stopcock (I) below a small receptacle (R) with a ground glass socket. The latter can be closed precisely by a ground cone fitted with a straight hose connection which terminates in a short glass T-tube. The horizontal limbs of the small T-tube are provided with a stopcock (II) and a rubber pear (A). On the vertical part of the $T$-tube, there is a mark $M$, a few $\mathrm{cm}$ above the ground cone.

The right leg of the $Y$-tube is made of a small bore calibrated glass tube (a section of a microburette or pipette subdivided into $0.01 \mathrm{ml}$, or preferably $0.005 \mathrm{ml}$ divisions, is most suitable). The upper part of this tube is provided with a small funnel.

The lower leg of the Y-tube with a third stopcock (III), passes to the bottom of a rubber-stoppered bottle. The latter is flled to $3 / 4$ of its volume with filtered seawater (or seawater-formaline $4 \%$ ) to which a certain amount of a surface active agent (e.g. Tween 80 ) has been added. 
A short, glass T-tube enters the bottle through a second hole in the rubber stopper. The horizontal cross-piece of the T-tube is provided with a stopcock (IV) at 1 extremity, and a rubber pear $(B)$ at the other.

The whole device can be fixed to a wooden support.

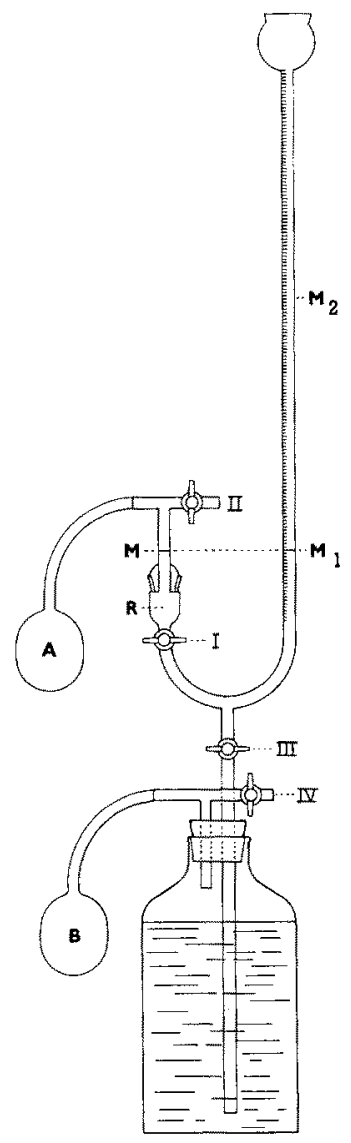

Fig. 1: Sketch of the volumeter. Explanation in the text

\section{Calibration procedure}

Open stopcocks I, II, III, and close IV. By pressing the rubber pear B, force water into the $\mathrm{Y}$-tube to a level exceeding M, then quickly close stopcock III. Open IV and, by slowly turning stopcock III, let the water level drop precisely to the point $\mathrm{M}$ in the left leg of the $\mathrm{Y}$-tube. The level $\mathrm{M}_{1}$ in the right leg must then be noted accurately. Now close stopcock II. Pressing pear A, force the water column from the left tube to the right tube (thus emptying the receptacle) and quickly close stopcock I. Remove the ground cone piece from the reservoir and replace it. Upon opening stop- 
cock $I$, the water flows back to the left tube and should reach the level $M$. By repeating this procedure several times the operational error can be determined.

Special attention should be paid to the following common sources of error: (a) Small water drops which adhere to the inner wall of the calibrated glass tube when the water flows back to the left tube. These can be prevented by adding more surface active agent to the water. (b) An air bubble, trapped when the receptacle is refilled, can be liberated by gently shaking or thrumming. (c) Small variations can be caused if the cone is improperly replaced in the socket.

It is inevitable that there will always be a degree of error, the magnitude being dependent upon the precision of the material used. In the device constructed, this error was about $0.005 \mathrm{ml}$.

\section{Measuring the volume of an organism}

Following the procedure described above, water is first adjusted in the glass tubes exactly to the $M, M_{1}$ level, and subsequently driven back into the right-hand calibrated tube; emptying the receptacle. The cone is removed from the socket, and the organism placed in the reservoir.

Difficulty has often been experienced in the removal of very small organisms from the receptacle. A satisfactory means of overcoming this problem is to place the organism in a small container with a perforated base, the volume of which can be measured separately by normal procedure.

The socket replaced, the water is allowed to flow back into the left part of the device exactly up to the level $M$. The water level in the graduated tube will now be $M_{2} . M_{2}-M_{1}$ is the volume of the animal.

\section{SUMMARY}

1. The volumeter described is a simple device, easy to construct and to handle.

2. It works on the principle of displacement of a water column and permits measurement of the volume of rather small invertebrates, down to 0.01 or even $0.005 \mathrm{ml}$.

\section{LITERATURE CITED}

Frolander, H. F., 1957. A plankton volume indicator. J. Cons. perm. int. Explor. Mer 22, $278-283$.

Gnanamuthu, C. P., 1952. A simple device for measuring the volume of an aquatic animal. Nature, Lond. 170, 587.

YentsCh, C. S. \& Hebard, J. F., 1957. A gauge for determining plankton volumes by the mercury immersion method. J. Cons. perm. int. Explor. Mer 22, 184-190.

Author's address: Dr. G. Persoone

Laboratory for Ecology

State University of Ghent

Ledeganckstraat 35

B-9000 Ghent, Belgium 